\title{
BMJ Open Patterns of initial opioid prescription and its association with short-term and long-term use among opioid-naïve patients in Malaysia: a retrospective cohort study
}

Che Suraya Zin, ${ }^{1}$ Nor llyani Nazar, ${ }^{1}$ Norny Syafinaz Abdul Rahman, ${ }^{1}$ Wan Rohaidah Ahmad, ${ }^{2}$ Nurul Sahida Rani, ${ }^{3}$ Kim Swan $\mathrm{Ng}^{4}$

To cite: Zin CS, Nazar NI, Rahman NSA, et al. Patterns of initial opioid prescription and its association with short-term and long-term use among opioid-naïve patients in Malaysia: a retrospective cohort study. BMJ Open 2019;9:e027203. doi:10.1136/ bmjopen-2018-027203

\section{- Prepublication history for} this paper is available online. To view these files, please visit the journal online (http://dx.doi. org/10.1136/bmjopen-2018027203).

Received 11 0ctober 2018 Revised 1 April 2019 Accepted 13 June 2019
Check for updates

(C) Author(s) (or their employer(s)) 2019. Re-use permitted under CC BY-NC. No commercial re-use. See rights and permissions. Published by BMJ.

For numbered affiliations see end of article.

Correspondence to Dr Che Suraya Zin; chesuraya@iium.edu.my

\section{ABSTRACT}

Objective This study examined opioid prescription initiation patterns and their association with short-term and long-term opioid use among opioid-naïve patients. Design This study was designed as a retrospective cohort study.

Setting and participants In this study, we analysed the prescription databases of tertiary hospitals in Malaysia. This study included patients aged $\geq 18$ years with at least one opioid prescription (buprenorphine, morphine, oxycodone, fentanyl, dihydrocodeine or tramadol) between 1 January 2011 and 31 December 2016. These patients had no opioid prescriptions in the 365 days prior, and were followed up for 365 days after the initial opioid prescription.

Main outcome measures The main outcome measures were the number of short-term ( $<90$ days) and long-term opioid users ( $\geq 90$ days), initial opioid prescription period and daily dose.

Results There were 33752 opioid-naïve patients who received opioid prescriptions ( $n=43432$ prescriptions) during the study period. Of these, $29824(88.36 \%)$ were short-term opioid users and 3928 (11.64\%) were long-term opioid users. The majority of these short-term $(99.09 \%)$ and long-term users $(96.18 \%)$ received an initial daily opioid dose of $<50 \mathrm{mg} /$ day with a short-acting opioid formulation. Short-term opioid users were predominantly prescribed opioids for $3-7$ days $(59.06 \%)$ by the emergency department (ED, $60.56 \%)$, while long-term opioid users were primarily prescribed opioids for $\geq 7$ days $(91.85 \%)$ by non-ED hospital departments $(91.8 \%)$. The adjusted model showed that the following were associated with long-term opioid use: increasing opioid daily doses, prescription period $\geq 7$ days and long-acting opioids initiated by non-EDs.

Conclusions The majority of opioid-naïve patients in tertiary hospital settings in Malaysia were prescribed opioids for short-term use. The progression to long-term use among opioid-naïve patients was attributed to the prescription of higher opioid doses for a longer duration as well as long-acting opioids initiated by non-ED hospital departments.
Strengths and limitations of this study

- The novel use of initial prescription data to identify patient characteristics associated with short-term and long-term use of opioids is a strength.

- The findings are robust as the analysis addressed all aspects of the study and results were based on a large sample from tertiary care settings.

- The analysis did not consider opioid prescriptions outside of tertiary hospitals.

- Identified associations cannot be assumed as causal.

\section{INTRODUCTION}

In the last three decades, the number of opioid prescriptions for non-cancer pain has increased significantly. ${ }^{12}$ Short-term use of opioids is appropriate for some acute pain conditions but long-term use ( $\geq 90$ days) for chronic non-cancer pain is controversial as there is limited evidence available regarding the benefits of long-term opioid use in chronic non-cancer pain. ${ }^{3}$ With the increasing long-term use of opioids for chronic non-cancer pain, there has been a concomitant increase in the risk of adverse events, abuse of prescribed opioids, as well as opioid overdose-related deaths. ${ }^{5-8}$

The treatment of acute pain is often a starting point for long-term therapy. In minimising the occurrence of long-term use, the Center for Disease Control and Prevention (CDC) recommended that opioids should be prescribed for less than 3 days for acute pain, and treatment for more than 7 days is seldom required. $^{9}$ Furthermore, opioid therapy should not be initiated with long-acting opioids or extended-release formulations.

The attributes of high-risk patients receiving opioids are well documented 
but less attention has been given to high-risk patterns of initial opioid prescription. Limited data are available regarding the way in which opioid-naive patients continue opioid therapy after initial opioid prescription, and to what extent it is used as short-term or long-term therapy. To date, studies evaluating opioid prescriptions have been conducted primarily in the USA and similar information from other parts of the world is very limited. As such, the present study aims to provide information on initial opioid prescriptions in Malaysia. It was designed to evaluate the association between the characteristics of initial opioid prescriptions and the receipt of short-term or long-term opioid therapy in opioid-naïve patients in outpatient tertiary hospital settings in Malaysia. The characteristics of initial opioid prescription evaluated here include the daily dose, initial prescription period, formulation types and prescription source.

\section{METHODS}

\section{Patient and public involvement}

There was no direct involvement of patients or public in this study, the data were deidentified, and only aggregate results were reported. Therefore, the requirement for informed consent was waived.

\section{Study design and setting}

This retrospective cohort study obtained data from the pharmacy databases of two tertiary outpatient public hospital settings in Malaysia. These hospitals have 800-1000 inpatient beds per hospital, and perform most disciplines including anaesthesiology, gastroenterology, hepatobiliary surgery, rheumatology, vitreoretinal surgery, hepatology, general surgery, pain management, microsurgery, colorectal surgery and renal services. This study included data collected between 1 January 2011 and 31 December 2016.

Data extracted from the pharmacy database included drug names and strengths, quantities, frequencies, issuing departments, prescription dates, and patients' age and gender. Age was recorded as that on the date of the first prescription reported in the database. This study included all patients aged $\geq 18$ years with at least one opioid prescription (buprenorphine, morphine, oxycodone, fentanyl, dihydrocodeine and tramadol) between 1 January 2011 and 31 December 2016, without any opioid prescriptions for the previous 365 days prior. Patients who received opioid prescriptions in the previous 365 days were excluded from the study. The patients included are defined as opioid-naïve patients. A 365-day washout period was also used in a previous study. ${ }^{10}$ The first opioid-naive prescription after the previous 365 days interval was considered the index prescription. Patients were followed up for 365 days after the index prescription with the first opioid prescription received between 1 January 2012 and 1 January 2015.

Prescriptions issued by the palliative care department $(4.04 \%)$ and prescriptions for aqueous morphine used as needed (17.3\%), primarily for cancer pain, were excluded. As details of patient diagnoses could not be retrieved from the pharmacy database, this exclusion would most likely ensure that the study population represented only non-cancer patients. This study excluded from the analysis approximately $1 \%$ of prescriptions with incomplete information or with values for dose or prescription period greater than twice the 99th percentile value (outliers).

\section{Short-term and long-term opioid users}

Patients were considered short-term opioid users if they were prescribed opioids for $<90$ days/year, or long-term opioid users if opioids were prescribed for $\geq 90$ days/year after the index prescription. A period of $\geq 90$ consecutive days was used as an indicator of long-term opioid use in a previous study. ${ }^{11}$

\section{Opioid days of supply}

The days of supply of initial opioid prescription period was calculated by dividing the quantity of opioid supplied by the number of daily doses (frequency). The days of supply of the initial opioid prescription was categorised as $<3,3-7$ and $>7$ days. The total number of days of opioid prescription during the 12 months following the index prescription for each patient was calculated and categorised as short-term use ( $<90$ days/year) or long-term use ( $\geq 90$ days/year). Opioid prescriptions with overlaps in the days of supply within the 12 months considered were subtracted.

\section{Opioid daily dose}

The initial opioid dose was converted to oral $\mathrm{mg}$ of morphine equivalents (MME) by multiplying by the conversion factor provided by the CDC. ${ }^{12}$ For each patient, the total MME opioid dose was divided by the initial total number of days prescribed to derive the opioid dose per day as MME. For example, the total MME dose for a prescription for $10 \mathrm{mg}$ oxycodone two times a day for 14 days was $420 \mathrm{MME}(10 \times 2 \times 1.5$ (equal analgesic ratio) $x 14$ days $=420 \mathrm{MME}$ ). If patients received multiple initial opioid prescriptions on the same day, the doses were merged and a combined daily dose was calculated as MME. The total dose per day per patient for the initial prescription was stratified as $>50,50-100$ and $>100 \mathrm{mg} /$ day, and the number of patients in each category was quantified.

\section{Short-acting and long-acting opioid formulations}

Short-acting opioid formulations include tablets, capsules and syrup, such as tramadol and dihydrocodeine tablets, immediate-release oxycodone and morphine syrup. Controlled-release, extended-release, modified-release and prolonged-released formulations are long acting and include controlled-release morphine and oxycodone, and fentanyl and buprenorphine patches. Information regarding the formulation was obtained from the hospital drug formulary. The number of patients initially receiving short-acting or long-acting opioids was calculated. 


\section{Source of initial opioid prescription}

The source of initial opioid prescription was categorised according to whether the prescription was issued from the emergency department (ED) or non-emergency hospital departments (non-ED). Non-ED departments included medical, surgical and anaesthesiology departments. Opioid prescribers from the ED were not limited to emergency physicians. The number of patients receiving the initial opioid prescription from ED or non-ED was recorded.

\section{Data analysis}

Patient characteristics and demographics were summarised as counts and percentages or as means $\pm \mathrm{SD}$ . Categorical variables were analysed using $\mathrm{X}^{2}$ or Fisher's exact tests, and continuous variables were analysed using Student's t-tests or rank sum tests.

Multivariate logistic regression was used to measure the association between the characteristics of initial opioid prescription (daily dose, prescription period, short-acting or long-acting formulation and source of prescription) and long-term opioid use. The reference group included short-term opioid users and the analyses were adjusted for the effects of age and sex. Adjusted ORs (aORs) and 95\%
CIs were used to summarise the association. Two-sided $\mathrm{p}$ values (significance: $\mathrm{p}<0.05$ ) were used in statistical tests. Stata software V.13.1 (StataCorp) ${ }^{13}$ was used in all analyses. The Strengthening the Reporting of Observational Studies in Epidemiology cohort reporting guidelines were followed in this study.

\section{RESULTS \\ Number of patients}

In total, 33752 opioid-naïve patients received at least one opioid prescription $(\mathrm{n}=43432)$ during the study period. Of these, $29824(88.36 \%)$ remained short-term opioid users (<90 days) and 3928 (11.64\%) became long-term opioid users ( $\geq 90$ days, figure 1$)$. In all opioid-naïe patients, there were more male $(54.28 \%)$ than female patients, and more Malay patients (49.93\%) than patients of other races. The average age was 49.5 years (table 1 ). Short-term opioid users comprised more males $(56.06 \%)$ than females and included mainly patients aged 18-40 years $(39.1 \%)$. The long-term opioid user group included more females $(59.24 \%)$ than males and consisted primarily of patients aged $61-80$ years $(43.25 \%)$. The

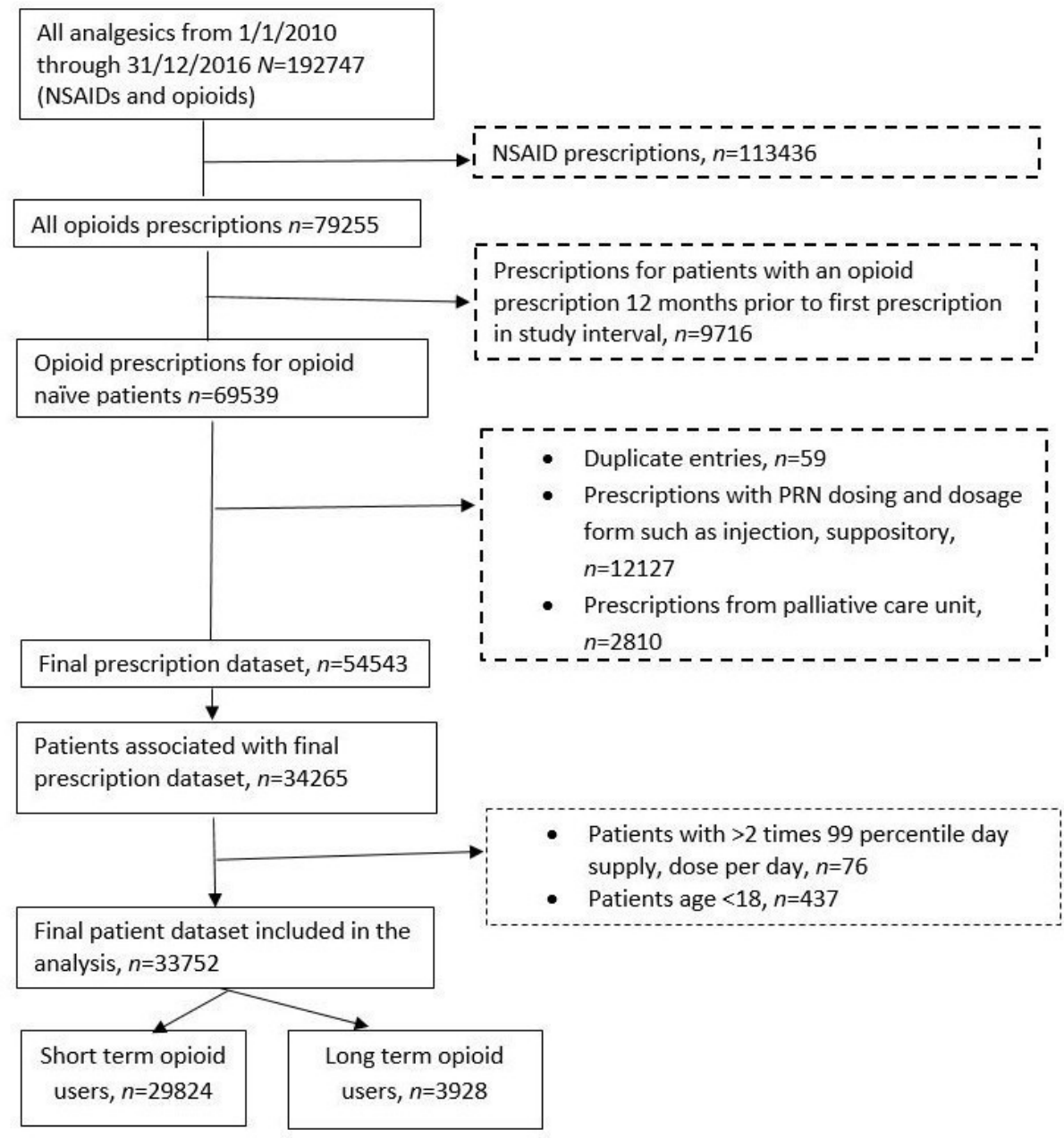

Figure 1 Cohort flow chart. NSAID, non-steroidal anti-inflammatory drug; PRN, when necessary. 
Table 1 Patient demographics

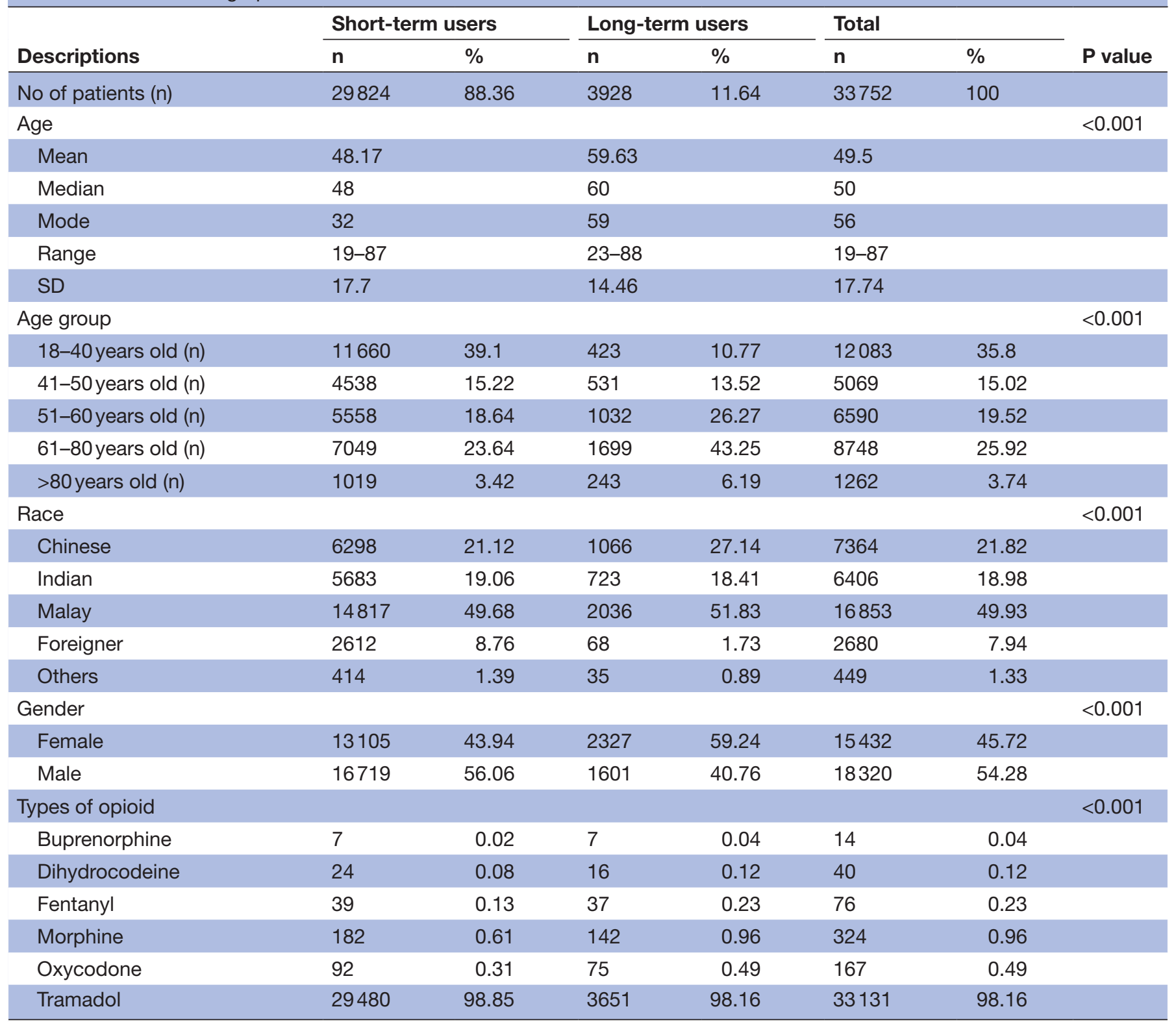

Unadjusted $\mathrm{p}$ values were estimated with the use of Student's t-test for continuous or $\mathrm{X}^{2}$ test for categorical variables for comparing shortterm and long-term users. Types of opioid refer to opioid during the first opioid prescription.

age difference between the short-term and long-term opioid users was significant $(\mathrm{p}<0.001)$. In both groups, Malay patients were predominant (short term, $49.68 \%$; long term, 51.83\%) compared with Chinese $(21.12 \%$ and $27.14 \%$, respectively), Indian (19.06\% and $18.41 \%$, respectively), foreigners $(8.76 \%$ and $1.73 \%$, respectively) and others $(1.39 \%$ and $0.89 \%$, respectively).

\section{Opioid days of supply}

Initially, short-term opioid users were most commonly prescribed opioids for 3-7 days (59.06\%), followed by $\geq 7$ days $(37.02 \%)$. Long-term opioid users were more frequently prescribed opioids for $\geq 7$ days (91.85\%), followed by $3-7$ days $(7.64 \%$, figure 2$)$. The mean period of initial opioid prescription was $12.93 \pm 11.63$ days for short-term users and 77.14 \pm 58.0 days for long-term opioid users.

An opioid prescription period of 3-7 days $(\mathrm{aOR}=1.05$, $95 \%$ CI 0.669 to 1.673 ) was not associated with progressing to long-term opioid use. However, if a patient received an initial prescription of $>7$ days, the odds of becoming a long-term opioid user were significantly increased (aOR=16.47, 95\% CI 10.55 to 25.69, table 2).

\section{Opioid daily dose}

The majority of short-term $(99.02 \%)$ and long-term opioid users $(96.0 \%)$ received a daily dose of $<50 \mathrm{mg} /$ day MME during their initial opioid prescription. Less than $1 \%$ of short-term users received $\geq 50 \mathrm{mg}$ /day (50-100 mg/day, $0.83 \%$; >100 mg/day, $0.15 \%$; figure 2 ). 


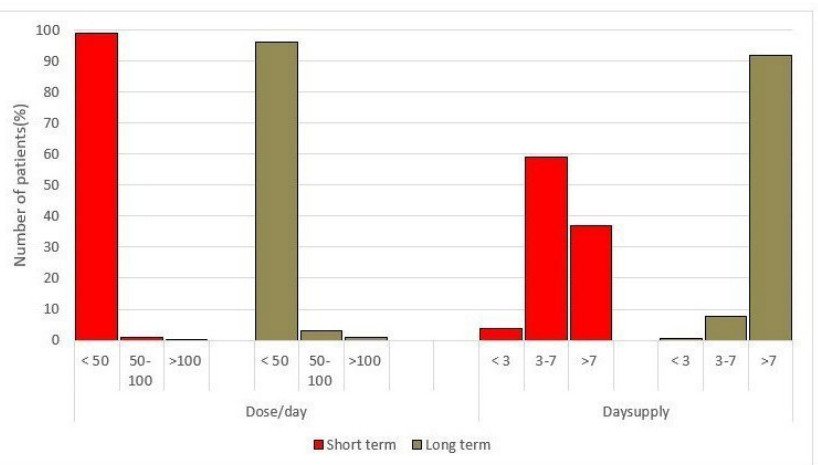

Figure 2 Dose per day and day supply per patient in patients who became short-term or long-term users after the initiation of opioid.

With regard to long-term opioid users, approximately $4 \%$ received $\geq 50 \mathrm{mg} /$ day $(50-100 \mathrm{mg} /$ day, $3.05 \%$; $>100 \mathrm{mg} /$ day, $0.94 \%)$. The mean opioid dose per day during the initial prescription was similar in short-term users $(30.4 \pm 8.84 \mathrm{mg})$ and long-term users $(30.6 \pm 18.17 \mathrm{mg})$. Results of the logistic regression analysis revealed that receiving opioid doses of $50-100 \mathrm{mg} /$ day $(\mathrm{aOR}=3.79$, $95 \%$ CI 3.0 to 4.78$)$ and $>100 \mathrm{mg} /$ day $(\mathrm{aOR}=7.12,95 \% \mathrm{CI}$ 4.5 to 11.26 ) significantly increased the odds of progress to long term use.

\section{Short-acting and long-acting opioid formulations}

Short-acting opioid formulations were the main forms used in both short-term (99.69\%) and long-terms users

\begin{tabular}{|c|c|c|c|c|}
\hline Predictors & ORs* & Wald & $P$ value & $95 \% \mathrm{Cl}$ \\
\hline \multicolumn{5}{|l|}{ Dose/day } \\
\hline $\begin{array}{l}50-100 \mathrm{mg} / \\
\text { day }\end{array}$ & 3.79 & 11.28 & $<0.001$ & 3.01 to 4.78 \\
\hline$>100 \mathrm{mg} /$ day & 7.12 & 8.39 & $<0.001$ & 4.50 to 11.27 \\
\hline \multicolumn{5}{|l|}{ Day supply } \\
\hline $3-7$ days & 1.06 & 0.24 & 0.807 & 0.67 to 1.67 \\
\hline$>7$ days & 16.47 & 12.35 & $<0.001$ & 10.56 to 25.70 \\
\hline \multicolumn{5}{|l|}{ Formulation } \\
\hline Long acting & 6.62 & 12.33 & $<0.001$ & 4.90 to 8.94 \\
\hline \multicolumn{5}{|l|}{$\begin{array}{l}\text { Source of } \\
\text { prescription }\end{array}$} \\
\hline Non-ED & 14.04 & 44.15 & $<0.001$ & 12.48 to 15.78 \\
\hline
\end{tabular}

Dose/day; reference ( $<50 \mathrm{mg} /$ day), day supply; reference $(<3$ days), formulation; reference (short-acting) source of prescription; reference (ED).

${ }^{*}$ Adjusted ORs and $p$ values were estimated with the use of logistic-regression models with occurrence of long-term opioid use in the 12 months after an initial opioid prescription as the dependent variable. The key covariate was the dose/day, day supply, opioid formulation and source of initial opioid prescription. All models were adjusted for age and sex.

ED, emergency department.

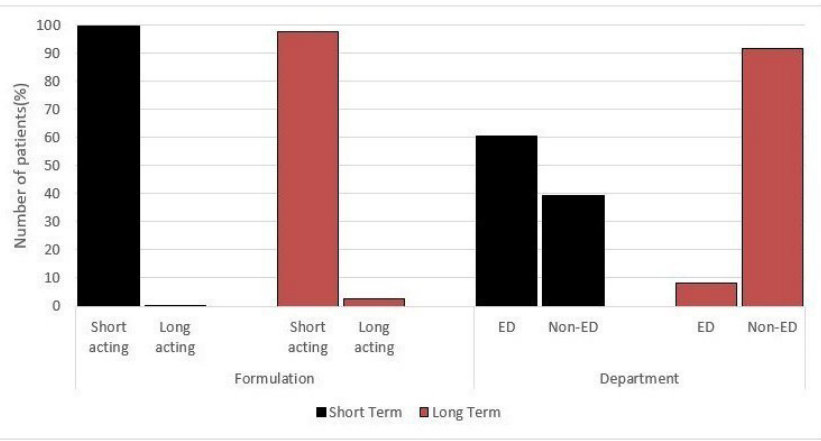

Figure 3 Department issuing the opioid and formulation of opioid during the initial prescription in patients who became short-term and long-term opioid user. ED, emergency department.

$(97.55 \%)$ in the initial prescription. Long-acting opioids were prescribed to $0.31 \%$ of short-term users and $2.42 \%$ of long-term users (figure 3). Tramadol was the initial short-acting formulation that was primarily prescribed to both study groups. The likelihood of becoming a longterm opioid user was significantly greater $(\mathrm{aOR}=6.62$, 95\% CI 4.90 to 8.94) when patients received long-acting opioid during the initial prescription.

\section{Source of initial opioid prescription}

Short-term opioid users commonly received initial opioid prescriptions from EDs (60.56\%), whereas longterm opioid users primarily received prescriptions from non-EDs $(91.8 \%$, figure 3$)$. When the model was adjusted for the effects of age and sex, initial prescriptions from non-EDs (aOR=14.03, 95\% CI 12.48 to 15.78$)$ were significantly associated with greater odds of becoming longterm opioid users.

\section{DISCUSSION}

The present study revealed that $11.6 \%$ of opioid-naive patients became long-term opioid users in the subsequent 365 days after receiving their initial opioid prescription in a Malaysian tertiary hospital setting. The adjusted model revealed that increasing opioid daily doses, initial prescription period of $>7$ days, use of long-acting opioids and prescriptions issued by non-EDs were associated with long-term opioid use.

Almost 12\% of opioid-naive patients progressed to long-term use, as is similar to that shown by a previous study, which reported that $13 \%$ of opioid-naïve patients continued to use opioids 90 days after surgical intervention. ${ }^{14}$ Other studies reported that $1.5 \%-27 \%$ of opioidnaïve patients progressed to long-term use after the initial opioid prescription. ${ }^{10}{ }^{15-20}$ The wide range of results reported in these studies may be affected by the use of different patient populations, which mostly included opioid-naive surgical patients. ${ }^{17} 1820$ Furthermore, various definitions of long-term opioid use were used in these respective studies, such as receiving $\geq 10$ prescriptions or receiving more than 120 days supply, ${ }^{17}$ receiving opioid 
prescriptions within 60 days of the 1-year anniversary of the surgery ${ }^{18}$ and receiving a 6 -month supply within the 12 months subsequent to an ED visit. ${ }^{20}$

The majority of short-term and long-term opioid users received a daily dose of $<50 \mathrm{mg}$ /day MME during their initial opioid prescription. In this study, approximately $1 \%$ of short-term users and $4 \%$ of long-term users received higher doses $(>50 \mathrm{mg} /$ day $)$ during their initial opioid prescription (short-term users: $50-100 \mathrm{mg}$ / day, $0.83 \%$, and $>100 \mathrm{mg} /$ day, $0.15 \%$; long-term users: $50-100 \mathrm{mg} /$ day, $3.05 \%$, and $>100 \mathrm{mg} /$ day, $0.94 \%$ ). These percentages are lower than those reported in a previous study, which found that approximately $20 \%$ (1 in 5-6 prescriptions) written were for $>50 \mathrm{mg} /$ day and up to $7 \%$ were written for $>90 \mathrm{mg} /$ day for opioid-naive patients in the non-ED settings. ${ }^{21}$ The current study recorded results for all opioid-naive patients regardless of whether their initial opioid prescription was from an ED or non-ED, and we expected prescriptions from non-EDs to be include higher doses than those reported in the previous study. This may explain the small number of opioid-naïve patients that were prescribed doses $>50 \mathrm{mg} /$ day in the current study.

For opioid-naïve patients who received initial doses of $>50 \mathrm{mg} /$ day, it is likely that they had previously received opioids at a similar dose for the treatment of a similar pain condition. ${ }^{21}$ They may also experience more persistent and severe pain that required higher doses of opioids. ${ }^{10}$ However, high doses $(>50 \mathrm{mg} /$ day) should be prescribed with caution as these may be associated with a higher risk of adverse events. A previous study reported that patients receiving $50-99 \mathrm{mg} /$ day or $>100 \mathrm{mg} /$ day showed a 3.7 -fold and 8.9-fold increase in overdose risk, respectively, compared with that in patients receiving $1-20 \mathrm{mg} /$ day. $^{22}$

With regard to the initial opioid prescription period, the current study showed that $37.02 \%$ of short-term opioid users and $91.85 \%$ of long-term opioid users received an initial prescription for $\geq 7$ days. This finding was generally consistent with that reported in a previous study, in which $>40 \%$ of prescriptions for opioid-naive patients issued by non-ED settings were for $>7$ days. ${ }^{21}$ Opioid-naïve patients with no previous opioid prescription likely experience acute pain or acute exacerbation of chronic pain, regardless of the setting. Because treatment for acute pain often leads to long-term opioid use, ${ }^{23}$ the CDC recommends the use of opioid therapy for $\leq 3$ days, and states that therapy for $>7$ days is seldom required. ${ }^{24}$ Contextual evidence review revealed that patients exposed to opioids will develop physiological responses a few days after the exposure. The likelihood of physical dependence increases with each day of unnecessary opioid use, without increasing the benefits. Furthermore, by decreasing the prescription period, the number of pills is minimised, which also reduces the potential for unintentional or intentional diversion. ${ }^{24}$

The present study also revealed that receiving an initial opioid prescription for $>7$ days was associated with the long-term use of opioids, which supports the CDC recommendation to limit the opioid supply to $3-7$ days to prevent patients from unnecessarily progressing to longterm opioid use. However, this initial prescription may not be a cause of long-term use, as this study was unable to include other factors likely contributing to long-term use, such as the persistence and severity of pain and a history of depression or substance abuse. Patients with these conditions are likely to receive more opioid prescriptions at higher doses. ${ }^{2526}$ Although these factors are difficult to evaluate in an observational study, this is the best design to provide insights into the risk associated with initial opioid prescription patterns. Randomised clinical trials may pose ethical challenges in assessing the above association and are unlikely to be performed. ${ }^{27}$ The current study has revealed that the majority of opioid-naive patients were prescribed short-acting opioids. Long-acting opioids were prescribed to $0.31 \%$ of short-term users and $2.42 \%$ of long-term users. Similar low rates of extended-release or long-acting $(>2 \%)$ formulations prescribed to opioidnaïve patients were also reported in a previous study. ${ }^{21}$ The current study also demonstrated that initial prescription of long-acting opioids was associated with greater risk of long-term use, as reported in previous studies. ${ }^{102}$ Furthermore, the risk of overdose was reportedly higher in opioid-naïve patients who were prescribed long-acting formulations compared with those who received immediate-release opioids. ${ }^{29}$

In the present study, tramadol was shown to be the initial short-acting formulation most commonly prescribed in both short-term and long-term opioid users. This is not surprising as tramadol is the main weak opioid available in the hospital settings considered in this study. Moreover, it does not require strict procedures, as is the case for controlled drugs such as dihydrocodeine and other opioids. A previous study reported that the probability of progressing to long-term opioid use after tramadol prescription was the second highest after prescription of long-acting opioids. ${ }^{28}$ Tramadol should be prescribed with caution as it was associated with a $145 \%$ increase in ED visits related to tramadol-associated adverse events. Furthermore, evidence for long-term efficacy of tramadol for pain management is limited. ${ }^{30}$

In terms of the source of prescription, the present study showed that opioid-naive patients who received prescriptions from the ED were less likely to progress to long-term opioid use $(8.2 \%)$. This finding is similar to that of a previous study, which reported that $1.1 \%-6.2 \%$ of opioid-naive patients progressed to long-term use if they received prescriptions from EDs. ${ }^{21}$ The present study has indicated that long-term opioid users $(91.8 \%)$ were more likely to have received initial prescriptions from non-EDs. This result is higher than that reported in a previous study (42\%-64\% (46\%-58\% less likely) $){ }^{21}$ This difference likely results from differences in the definitions of long-term use, as the current study used 90 days and the previous study used 120 days to define long-term use. 


\section{Strengths and weaknesses}

A number of limitations should be noted. This was an observational study and associations cannot be interpreted as causal, although our findings were robust and the analyses addressed all aspects of the study. The patient-level data available in the prescription database did not allow us to further adjust for the diagnoses and comorbidities of opioid-naïve patients that may confound the associations observed in this study. With no information regarding diagnoses, this study may overestimate the number of non-cancer patients despite excluding prescriptions from the palliative care department and prescriptions written 'as needed', primarily for aqueous morphine that is commonly used for patients with cancer. This study was limited to outpatient public tertiary hospital settings and the results cannot be generalised to inpatient hospitals, and private or primary care settings. This study refers to prescribing data and no information is available as to whether the medications were actually dispensed and consumed. This study was also unable to identify whether the patients were truly opioid naive, as these patients may have received opioid prescriptions from other healthcare settings such as other hospitals and health clinics, which were not captured in the databases surveyed in the present study. High opioid doses used in certain patients may indicate that such patients were not truly opioid naïve and may have visited other clinicians and previously used opioid therapy. This may lead to overestimation of the number of opioid-naive patients receiving high doses in this study.

\section{CONCLUSION}

In this study, $11.6 \%$ of opioid-naïve patients in tertiary care settings in Malaysia progressed to long-term opioid use after receiving an initial opioid prescription. Increasing opioid daily doses, initial prescription period $>7$ days, use of long-acting opioids and prescriptions issued by non-EDs are characteristics of initial opioid prescriptions that were associated with greater odds of progressing to long-term opioid use. Information regarding the high-risk characteristics of initial opioid prescriptions is important as acute opioid therapy can quickly progress to long-term use. This information may help clinicians to have greater control over opioid prescriptions to mitigate the chances of unintentional chronic use of opioids.

\section{Author affiliations \\ ${ }^{1}$ Department of Pharmacy Practice, Kulliyyah of Pharmacy, International Islamic University Malaysia - Kuantan Campus, Kuantan, Malaysia \\ ${ }^{2}$ Department of Anaesthesiology and Intensive Care, Hospital Sultanah Nur Zahirah, Kuala Terengganu, Malaysia \\ ${ }^{3}$ Department of Pharmacy, Hospital Sultanah Nur Zahirah, Kuala Terengganu, Malaysia \\ ${ }^{4}$ Department of Anaesthesiology and Intensive Care, Hospital Selayang, Batu Caves, Malaysia}

Acknowledgements We would like to thanks the staff of Information Technology of Hospital Sultanah Nur Zahirah Kuala Terengganu and Hospital Selayang, Selangor for assisting in data extraction
Contributors CSZ initiated and developed the research questions and study design, conducted data management and analysis, and led on drafting the manuscript. All of the authors (NIN, NSAR, WRA, NSR and KSN) contributed to the data acquisition, interpretation of the data, critically revised the manuscript and approved the final version submitted for publication.

Funding This work was supported by a research grant from The Ministry of Education Malaysia (Fundamental Research Grant Scheme, FRGS 15-195-0436).

Competing interests None declared.

Patient consent for publication Not required.

Ethics approval This study obtained ethical approval from the Medical Research Ethical Committee, Ministry of Health of Malaysia.

Provenance and peer review Not commissioned; externally peer reviewed. Data sharing statement № additional data are available.

Open access This is an open access article distributed in accordance with the Creative Commons Attribution Non Commercial (CC BY-NC 4.0) license, which permits others to distribute, remix, adapt, build upon this work non-commercially, and license their derivative works on different terms, provided the original work is properly cited, appropriate credit is given, any changes made indicated, and the use is non-commercial. See: http://creativecommons.org/licenses/by-nc/4.0/.

\section{REFERENCES}

1. National Institute on Drug Abuse. America's addiction to opioids: heroin and prescription drug abuse. https://www.drugabuse.gov/ drugs-abuse/opioids/opioid-overdose-crisis (Accessed 27 Apr 2018).

2. Centers for Disease Control and Prevention. Prescription opioid overdose data. Atlanta: Centers for Disease Control and Prevention, 2016.

3. Chou R, Turner JA, Devine EB, et al. The effectiveness and risks of long-term opioid therapy for chronic pain: a systematic review for a National Institutes of Health Pathways to Prevention Workshop. Ann Intern Med 2015;162:276-86.

4. Vowles KE, McEntee ML, Julnes PS, et al. Rates of opioid misuse, abuse, and addiction in chronic pain: a systematic review and data synthesis. Pain 2015;156:569-76.

5. Centers for Disease Control and Prevention. Opioid data analysis. https://www.cdc.gov/drugoverdose/data/analysis.html (Accessed 8 Sep 2018).

6. Bohnert AS, Ilgen MA, Trafton JA, et al. Trends and regional variation in opioid overdose mortality among Veterans Health Administration patients, fiscal year 2001 to 2009. Clin J Pain 2014;30:605-12.

7. Manchikanti L, Helm S, Fellows B, et al. Opioid epidemic in the United States. Pain Physician 2012;15:ES9-38.

8. Olsen Y. The CDC guideline on opioid prescribing: rising to the challenge. JAMA 2016;315:1577-9.

9. Dowell D, Haegerich TM, Chou R. CDC guideline for prescribing opioids for chronic pain-United States, 2016. JAMA 2016;315:1624-45.

10. Deyo RA, Hallvik SE, Hildebran C, et al. Association between initial opioid prescribing patterns and subsequent long-term use among opioid-na??ve patients: a statewide retrospective cohort study. J Gen Intern Med 2016.

11. Dobscha SK, Morasco BJ, Duckart JP, et al. Correlates of prescription opioid initiation and long-term opioid use in veterans with persistent pain. 2014;29:102-8.

12. Centers for Disease Control and Prevention. CDC compilation of opioid analgesic formulations with morphine milligram equivalent conversion factors. 2015. http://www.pdmpassist.org/pdf/BJA_performance_ measure_aid_MME_conversion.pdf (Accessed 27 Aug 2018).

13. StataCorp. Stata: Release 15. College Station, TX: StataCorp LLC, 2015.

14. Johnson SP, Chung KC, Zhong L, et al. Risk of prolonged opioid use among opioid-naïve patients following common hand surgery procedures. J Hand Surg Am 2016;41:947-57.

15. Hooten WM, St Sauver JL, McGree ME, et al. Incidence and risk factors for progression from short-term to episodic or long-term opioid prescribing: a population-based study. Mayo Clin Proc 2015;90:850-6.

16. Shah A, Hayes CJ, Martin BC. Characteristics of initial prescription episodes and likelihood of long-term opioid use - United States, 2006-2015. MMWR Morb Mortal Wkly Rep 2017;66:265-9.

17. Sun EC, Darnall BD, Baker LC, et al. Incidence of and risk factors for chronic opioid use among opioid-naive patients in the postoperative period. JAMA Intern Med 2016;176:1286-93. 
18. Alam A, Gomes $\mathrm{T}$, Zheng $\mathrm{H}$, et al. Long-term analgesic use after low-risk surgery: a retrospective cohort study. Arch Intern Med 2012;172:425-30.

19. Barnett $M L$, Olenski AR, Jena AB. Opioid-prescribing patterns of emergency physicians and risk of long-term use. N Engl J Med 2017;376:663-73.

20. Brummett CM, Waljee JF, Goesling J, et al. New persistent opioid use after minor and major surgical procedures in US Adults. JAMA Surg 2017; 152:e170504.

21. Jeffery MM, Hooten WM, Hess EP, et al. Opioid prescribing for opioid-naive patients in emergency departments and other settings: characteristics of prescriptions and association with long-term use. Ann Emerg Med 2018;71:326-36.

22. Dunn KM, Saunders KW, Rutter CM, et al. Opioid prescriptions for chronic pain and overdose: a cohort study. Ann Intern Med 2010;152:85-92.

23. Edlund MJ, Martin BC, Russo JE, et al. The role of opioid prescription in incident opioid abuse and dependence among individuals with chronic noncancer pain: the role of opioid prescription. Clin J Pain 2014;30:557-64.

24. Dowell D, Haegerich TM, Chou R. CDC Guideline for prescribing opioids for chronic pain--United States, 2016. JAMA 2016;315:1624-45.
25. Sullivan MD, Howe CQ. Opioid therapy for chronic pain in the United States: promises and perils. Pain 2013;154:S94-S100.

26. Edlund MJ, Martin BC, Devries A, et al. Trends in use of opioids for chronic noncancer pain among individuals with mental health and substance use disorders: the TROUP study. Clin J Pain 2010;26:1-8.

27. Deyo RA, Hallvik SE, Hildebran C, et al. Association between initial opioid prescribing patterns and subsequent long-term use among opioid-naïve patients: a statewide retrospective cohort study. J Gen Intern Med 2017;32:21-7.

28. Shah A, Hayes CJ, Martin BC. Characteristics of initial prescription episodes and likelihood of long-term opioid use - United States, 2006-2015. MMWR Morb Mortal Wkly Rep 2017;66:265-9.

29. Miller M, Barber CW, Leatherman S, et al. Prescription opioid duration of action and the risk of unintentional overdose among patients receiving opioid therapy. JAMA Intern Med 2015;175:608-15.

30. Bush D. The CBHSQ report: emergency department visits for adverse reactions involving the pain medication tramadol. Rockville, MD: US Department of Health and Human Services, Substance Abuse and Mental Health Services Administration, Center for Behavioral Health, 2015. 